\title{
Investigating Consumption-Related Emotions Elicited by Selected Dairy Products Using Product Emotion Measurement
}

\author{
Valery Y. Yao ${ }^{1}$ \\ ${ }^{1}$ University of South Africa, South Africa \\ Correspondence: Valery Y. Yao, PhD Candidate, Bureau of Market Research, Department of Business \\ Management, University of South Africa, Pretoria, South Africa. Tel: 27-73-110-8163. E-mail: \\ yaovalery@gmail.com
}

Received: December 10, 2015 Accepted: December 23, $2015 \quad$ Online Published: January 28, 2016

doi:10.5539/ijms.v8n1p86 URL: http://dx.doi.org/10.5539/ijms.v8n1p86

\begin{abstract}
This article investigates the mediating role of specific emotions attached to the consumption of milk, yoghurt, cheese, and maas (Note 1) in Gauteng Province, South Africa. To this end, 81 South African dairy consumers' consumption experiences were assessed through the use of the Product Emotion measurement (PrEmo). Computer-aided web interviews (CAWI) were used to collect the data. The findings indicate that ultimately, dairy consumption is emotionally-driven. The findings also clearly offer strong support that the notion of consumer emotion is a much better indicator for assessing and improving consumer experience. The uncovered strong emotions elicited by the selected generic dairy products should be considered by dairy marketers as critical building blocks in creating dairy marketing messages. Measuring consumers' consumption experience as integral part of a marketing programme is the first study of its kind in the South African dairy industry.
\end{abstract}

Keywords: consumption emotions, product experience, dairy products, product emotion measurement (PrEmo)

\section{Introduction}

Most approaches to decision-making usually have a high regard on rational cognitive variables in explaining human performance. For example, economic theories contend that individual consumption decisions are governed by variables such as disposable income and interest rate. The utilitarian perspective of decision-making has also dominated consumer behaviour literature, with consumers being, for decades, assumed to exhibit a rational approach to decisions, with scant regard to the nature of products. The fundamental question that drives research in this area is 'why consumers who are presented with the same options make different choices' (Gutnik, Hakimzada, Yoskowitz, \& Patel, 2006) or the mechanisms consumers use to cope with the vast array of information with which they are presented. Building on unanswered issues left by rationally-led theories, a revolution in emotion research has emerged in the last few decades, engendering a paradigm shift in thinking about decision theories (Lerner, Li, Valdesolo, \& Kassam, 2014). Empirical studies provide evidence of the emotional component of consumption decisions. According to Percy, Hansen, \& Randrup (2004), emotional memories are attached to all that consumers experience, including brands. Similarly, Schoefer (2008) reports that emotions are well-known for their ability to predict customers' judgments, while Desmet (2002) maintains that emotions evoked by products enhance the pleasure of buying, owning and using them. Therefore, there is a need to provide a context-specific case to ascertain the emotionality of consumers in consuming dairy products.

The purpose of this article is to report on the findings of a larger study that set out to ascertain the specific emotionality attached to milk, yoghurt, cheese and maas consumption in Gauteng Province, South Africa.

This research has extended the scope of the use of consumption-related emotions in decision-making by positioning emotional response as a key indicator in improving buying behaviour and consumption experience. With this research being one of the first in the South African dairy industry to incorporate emotions in addressing consumption issues, it will assist dairy marketers or other policy makers to identify priorities and interventions. This article begins by providing an overview of the existing knowledge on product experience. Then follow an examination of previous research on emotional response, and, more specifically, studies that have focused on the effects of emotions consumption experience. An innovative research instrument, PrEmo, used in this study to examine the emotional response of South African consumers to the selected dairy products, is introduced. A discussion of the results and implications for future research concludes the article. 


\section{Literature Review}

\subsection{The Context of the Study}

The dairy industry is the fifth largest agricultural industry in South Africa, representing $5.6 \%$ of the gross value of all agricultural production. The contribution of milk production in South Africa is approximately $0.5 \%$ to the world milk production. However, in terms of value, the South African dairy market generated R17.2 billion in 2009 and as at December 2011, this figure reached R23 billion (Yao, 2013). The industry comprises of a number of different economic activities and there are significant differences between farming methods and processing of dairy products. These activities involve the production and marketing of raw milk, pasteurized milk and cream, fermented milk, long-life milk and cream, yoghurt, cheese and its by-product whey, milk powder, sweetened and unsweetened concentrated milk, butter and butter oil (Department of Agriculture, Forestry \& Fisheries, 2011). In 1996, the dairy industry was deregulated, turning it from a single channel marketing system to a more competitive free-market (Bandama, 2011). A number of issues, including the decrease in the number of dairy producers and general consumption as well as misconceptions about dairy products (Yao, 2013), were noticed. One of the avenues to address the issue of the decrease in consumption was to design new marketing initiatives towards consumers (NAMC, 2001). Within this avenue, it is suggested to investigate the emotional connection of consumers with dairy products for increased engagement.

\subsection{Product Experience}

The concept of emotion has had a profound impact on various research areas including advertising and marketing (Richins, 1997). Research by Desmet (2002) in the area of design has translated an unprecedented emergence of product experience in marketing. Transactional marketing was grounded on the fact that when a customer has bought a product, it does not forecast the probability of a new purchase, not even if a series of purchases has been made (Brink \& Berndt, 2008). Researchers in that era, with a short-term vision underestimated the consumer as a potential source of investment possibilities (Shien \& Yazdanifard, 2014). However, the concept of relationship marketing, ennobled marketing in claiming that sacred relationships develop between consumers and their brands or products through interactions (Bordegoni, 2013; Abubakar \& Mokhtar, 2015). Through this philosophy, marketing researchers have come to realise the richness of understanding consumers from a variety of perspectives, including consumption. Kim, Sullivan, \& Forney (2007) even claim that consumption is a catalyst of consumer knowledge and, consequently, a powerful source of identification of marketing strategies. From this perspective, consumption is elevated to a cultural system characterised by the simultaneous deployment of images, pictures and concepts, creation of affect, and mobilisation of the body (Schroeder \& Zwick, 2004) as depicted in Figure 1.

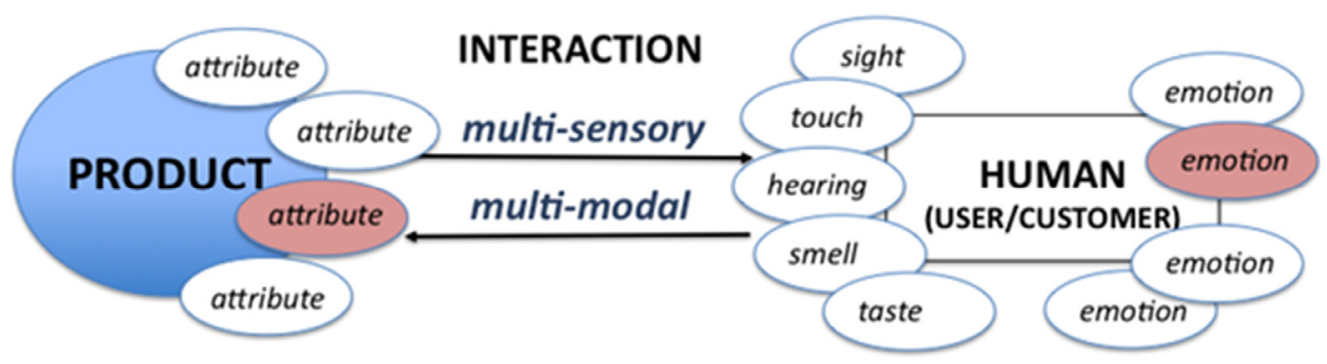

Figure 1. Correlation of product attributes and elicited emotions

Source: Bordegoni (2013).

Consumption becomes an adventure with consumers constantly being in search for experiences that stimulate, elicit psychological excitement, and produce sensory pleasure (Kim et al., 2007). Furthermore, conceptualisation of consumption experience led to sensory consumption. Krishna (2010) defines consumption as consumption of products or experiences that engage the senses of the consumer; a consumption experience that is processed through one or more of the five sensory modalities of taste, vision, sound, smell and touch. Previous research suggests three components of product experience, namely; aesthetics, meaning and emotions. In fact, consumers' attraction, awareness, discovery, cultivation, advocacy, purchase and use of a product engender a holistic experience, the result of a constant interaction of these three components (Fokkinga, Hekker, Desmet, \& Özcan, 2014). 


\subsection{Utilitarian versus Hedonic Consumption}

In positioning consumption in the economic life cycle, Goodwin, Nelson, Ackerman, \& Weisskopf (2008) define consumption as the process by which goods and services are put to final use by people. Previous research on consumption appears to be diverse. For example, some economic research has focused more attention on income, disposable income, and interest rate as influential factors on national and household decision-making. Others have revealed that consumption is shaped by dynamics such as age and gender (Lucier \& Lin, 2001; Mitchell \& Walsh, 2004). The common ground of those studies is that the consumer is portrayed as 'an instrumentally rational consumer'. In the field of consumer behaviour, most models of consumer behaviour adopted this approach (Engel, Blackwell, \& Miniard, 1993; Peter \& Olson, 1987; Schiffman \& Kanuk, 1997). With regard to decision making, two major approaches seem to emerge; the utilitarian and hedonic decision making. The utilitarian approach borrowed from economists, has historically suggested that decision-making was viewed as a cognitive process, a matter of making a choice with the intention of maximising the positive consequences (Wanglee, 2011). From a theoretical and empirical point of view, the utilitarian approach to decision-making, with a strong emphasis on rationality, was challenged in terms of shortcomings. World-renowned consumer researchers, Holbrook \& Hirschman (1982) pointed to the possibility and potential benefits of advancing consumer behaviour research away from the rational approach simply because it would neglect important consumption phenomena. In fact, it has been criticised for lack of realism (Erasmus, Boshoff, \& Rousseau, 1991). Therefore, efforts to understand and to remedy these concerns have paved the way to advocacy of hedonic consumption. Alba \& Williams (2012) define hedonic consumption as those facets of consumer behaviour that relate to the multisensory, fantasy, and emotive aspects of one's experience with chosen products. Put simply, consumers do not always purchase goal-directed or need-satisfying products. In most cases, consumption is portrayed as an 'adventure' with consumers seeking some pleasurable experiences ( $\mathrm{Li}$, Dong, \& Chen, 2011). In this regard, a number of writings sought to address how consumers' expectations influence, alter or hold their consumption (Ariely \& Norton, 2009). Even if these two approaches are not exclusive, which implies that many acts of consumption are driven by some combination of utilitarian and hedonic motives (Alba \& Williams, 2012), the discussion in this article relates to hedonic consumption. The central contention of this study is that consumption translates into emotional experiences that are unique to individual consumers, namely; consumers of dairy products (Kim et al., 2007; Andrade \& Cohen, 2007).

\subsection{Emotional Consumption Experience}

Caru \& Cova (2003) concluded their paper stating: 'to avoid finishing again in a dead-end similar to that already seen in relationship marketing, marketers must be able to take in the full breadth of a phenomenon such as experience, from the ordinary to the extraordinary'. A closer understanding of this statement informs that any interaction that a consumer has with a product or a service encounter develops or leaves an opinion, an attitude, or an experience on the part of the consumer. This experience serves as critical judgemental value for future decisions regarding consumption. Emotions have been shown to play an important role in consumers' evaluation of their consumption experiences. The concept of consumption emotion refers to, according to Hou, Xiaoding, \& $\mathrm{Hu}$ (2013) and Argan, Argan, \& Akyildiz (2014), the psychological response derived from acknowledgement of products and services in consumption. For example, modern shoppers, according to LaSalle \& Britton (2003) and Kim et al. (2007) are looking for something extraordinary, memorable and enjoyable. When consumption is viewed as a process, it can be divided into three or four phases (Caru \& Cova, 2003; Davis, 2002; Bonnefoy-Claudet \& Ghantous, 2013), namely; pre-consumption, actual and post-consumption. In each of the phases, a consumer may experience a number of emotions. In the discussion that follows, consumer emotional experience will embrace the three-phase classification.

Pre-consumption experience can be situated at the beginning of a consumption decision continuum, whereby the prospective consumer engages in a search for a particular product or service. One of the most popular situations where one expresses pre-consumption experience is crowding. It is commonly described as a psychological state of mind when a person's demand for space exceeds its supply (Kazakevičiūtè \& Banytè, 2012). Research investigating the effect of crowding reveals mixed findings. Most studies find a negative correlation between crowding and consumer satisfaction, with strong expressions of irritation, anger, disappointment, and stress. The second explanation builds on the fact that the emotional aspects are an important part of the service encounter whether the emotional benefits are at the core of the service or not. With regard to post-purchase consumption experience, there is always an experience associated with consuming products and services. However, this experience can be good or bad. The nature of post-purchase consumption experience should be measured against the initial expectation of the consumer (Honea \& Horsky, 2011). For example, when a consumer's expectations are matched or exceeded by a product with superior hedonic benefits, he develops strong positive experience, 
also referred to as consumer delight. The contrary results in consumer disappointment (Honea \& Horsky, 2011). From Pine \& Gilmore's (1998) perspective, the best consumption experiences are those that engage consumers in a unique and memorable way.

\section{Methodology}

\subsection{Research Approach}

In order to explore dairy consumers' emotive experiences associated with their consumption behaviour, a qualitative research design was adopted for this study for the following reasons. Ontologically, the approach followed in this study is that emotions are consistently credited with the high potential to influence judgement and choices in different spheres of life. Epistemologically, emotional responses elicited by products, services and ideas are reported to be crucial in determining the final outcome of decision-making. While positive emotions enhance the likelihood of acquiring, using and exhibiting patronage to products, services and ideas, negative emotions lead to brand avoidance.

\subsection{Research Participants and Instrument}

A non-probability sample of 81 South African dairy consumers from different background across the Gauteng Province participated in the study. The ethical aspects of the research were discussed with participants. Participation was voluntary and required a signed consent form. However, participants could withdraw from the research at any time. The recruitment criteria of participants comprised dairy consumption, LSM classification and age.

Studies in a number of contexts, including advertising, attitude, product usage, brand evaluation and consumption confirm different forms of consumer responses to different consumption situations (Kapoor, 2008). The study was about capturing emotional experiences of selected dairy consumers, based on the assumption that any interactions consumers have with a product or a brand leaves some positive or negative experiences on their memories (Percy, Hansen, \& Randrup, 2004; Joubert \& Poalses, 2014). Although Drozdova (2012) found explicit methods, such as explicit verbal self-report method very adequate in measuring emotional experience in empirical research, Richins (1997), on the contrary, concluded that these measures are completely unsuited for the purpose of measuring consumption-related emotions. As a result, Desmet (2002) developed the Product Emotion Measurement (PrEmo), a non-verbal instrument tool, consistently used in consumer research worldwide with a track record in emotion measurement. The PrEmo comprises a total of 14 possible emotions (cartoons). The Susa Group offers a more refined version of PrEmo that is used in this study. This version consists of 12 emotions. These include Desire, Satisfaction, Pride, Hope, Joy and Fascination and six negative emotions namely Disgust, Dissatisfaction, Shame, Fear, Sadness and Boredom. Participants express the intensity of the emotions as elicited by the stimulus on a 5-point scale (Sorensen, 2008). The PrEmo animations used in the questionnaire is displayed in Appendix.

PrEmo was identified as the most suitable instrument for this study for some reasons. Although the instrument is computerised, literacy is not a pre-requisite for participation. The PrEmo uniquely measures distinct secondary emotions, and it can be used cross-culturally as it does not ask participants to verbalise their emotions. In addition, it can measure mixed emotions, that is, more than one emotion experienced simultaneously. In this regard, Sorensen (2008) states that with PrEmo more than one specific emotion can be registered making it suitable to study mixed emotions. PrEmo is a user-friendly, valid, and inexpensive instrument to measure emotional reactions to advertising (Joubert, 2008).

\section{Data Analysis}

Due to the non-verbal nature of the instrument, participants were only presented with the animations without being pre-informed of the emotions depicted by each character in an attempt to elicit the most emotively authentic response. Respondents' data were captured in an Excel spreadsheet and exported to IBM SPSS (version 23) where after summative statistics were calculated to indicate intensities of emotive reactions.

\section{Results and Discussion}

Table 1 displays the mean score ratings of product users for the six positive and six negative PrEmo emotions elicited by each of the four dairy products. It should be noted that the ratings were captured on a 5-point measurement scale. 
Table 1. PrEmo emotive reactions to milk, cheese, yoghurt and maas

\begin{tabular}{lll}
\hline & Positive emotions & Negative emotions \\
\hline Milk & 2.6 & .5 \\
Cheese & 2.7 & .5 \\
Yoghurt & 2.9 & .5 \\
Maas & 2.1 & .9 \\
Average & 2.5 & .6 \\
\hline
\end{tabular}

The average positive emotions rating of 2.5 reflected in Table 1 is marginally lower than ratings found in similar surveys. However, the ratings do, however, differ with yoghurt, cheese and milk evoking stronger positive emotions than maas. This is not a surprising finding, given that the user base for maas is lower as compared to milk, cheese and yoghurt. The average 0.9 rating for negative emotions felt towards maas is also indicative of the lower user base and infrequent and non-users experiencing less intense emotions. A more detailed analysis of these mean scores by specific emotion is visually displayed in Figure 2 to Figure 9.

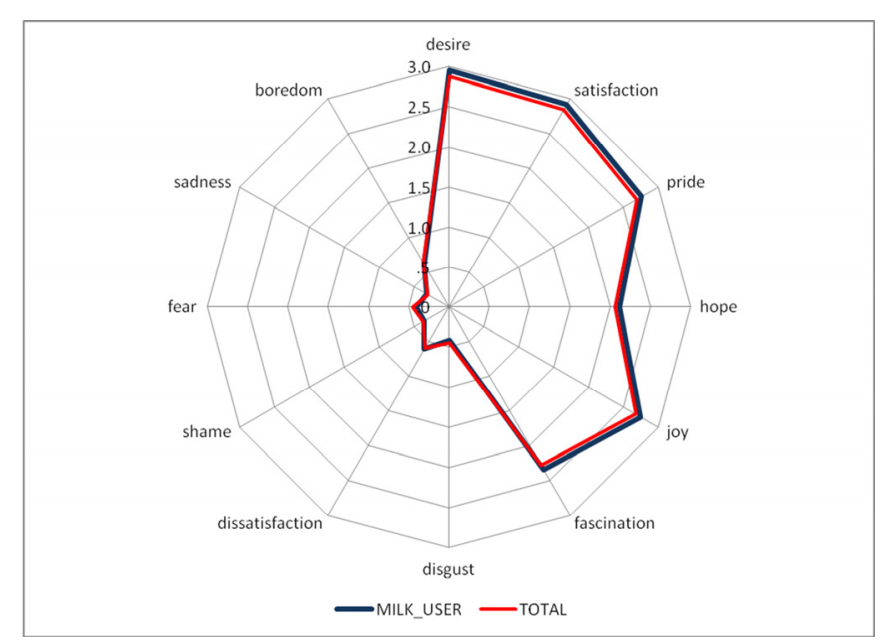

Figure 2. PrEmo milk users versus total

The user and total participant profiles reflected in Figure 2 are similar in shape, level and distribution, indicating the generic nature of milk with Desire, Satisfaction, Joy and Pride the salient emotions evoked. Due to a low non-user participant base $(n=2)$, an analysis of users versus non-users is not reflected as a result of insignificant findings from which no additional insights can be deducted.

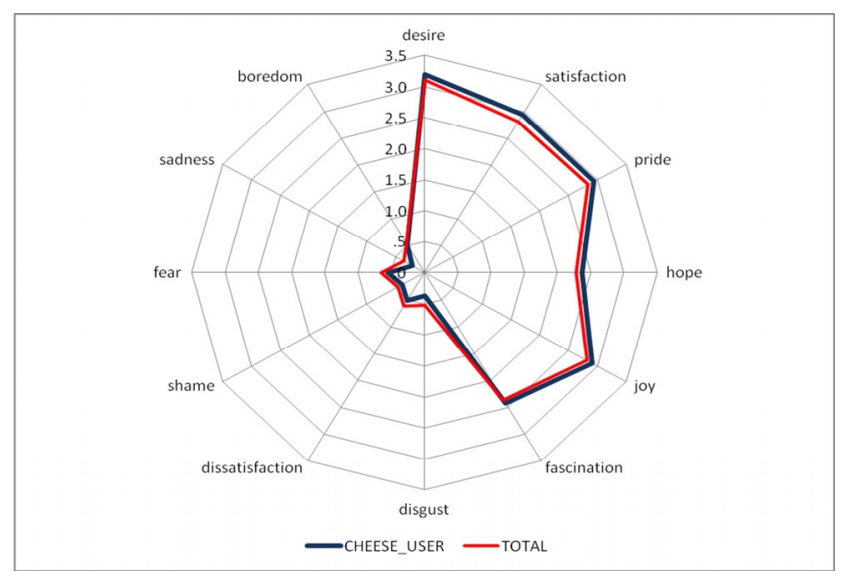

Figure 3. PrEmo cheese users versus total 
The user and total participant profiles reflected in Figure 3 are, as with milk, similar in shape and distribution. However, the level is marginally higher indicating slightly stronger positive emotions evoked. Desire, Satisfaction, Joy and Pride remain the salient emotions experienced.

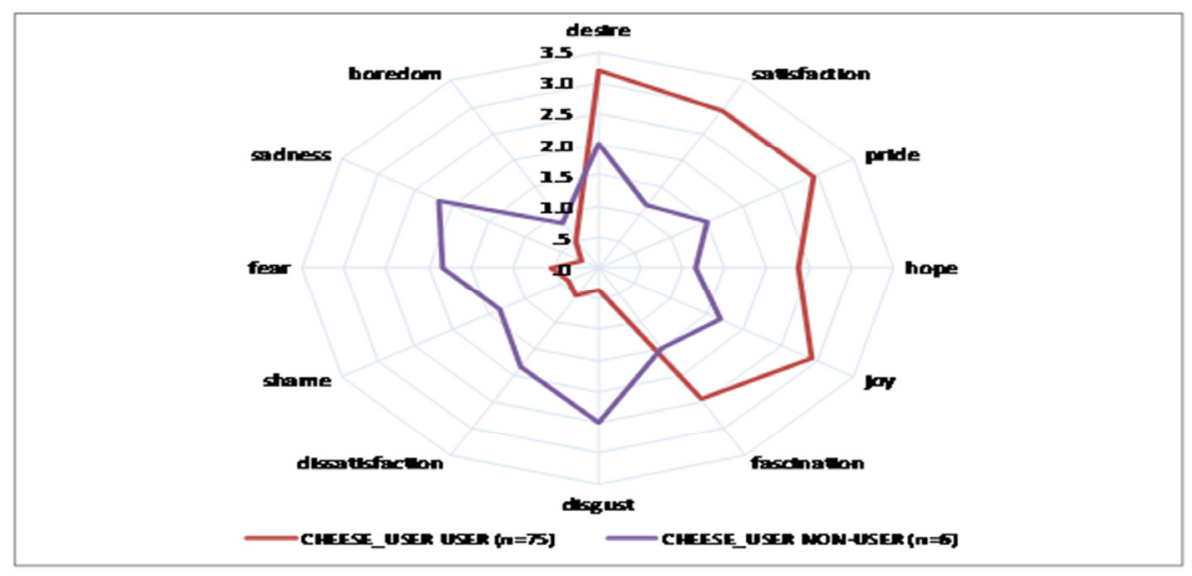

Figure 4. PrEmo cheese users versus non-users

Unlike milk, Figure 4 depicts that the user and non-user profiles of cheese differ in shape, level and distribution. Cheese evokes stronger feelings of Sadness, Fear and Disgust among non-users, whereas users experienced stronger Desire, Satisfaction, Pride and Joy as a result of being exposed to the product. Non-users clearly experience comparable emotive intensities irrespective of the positive or negative nature of the emotions.

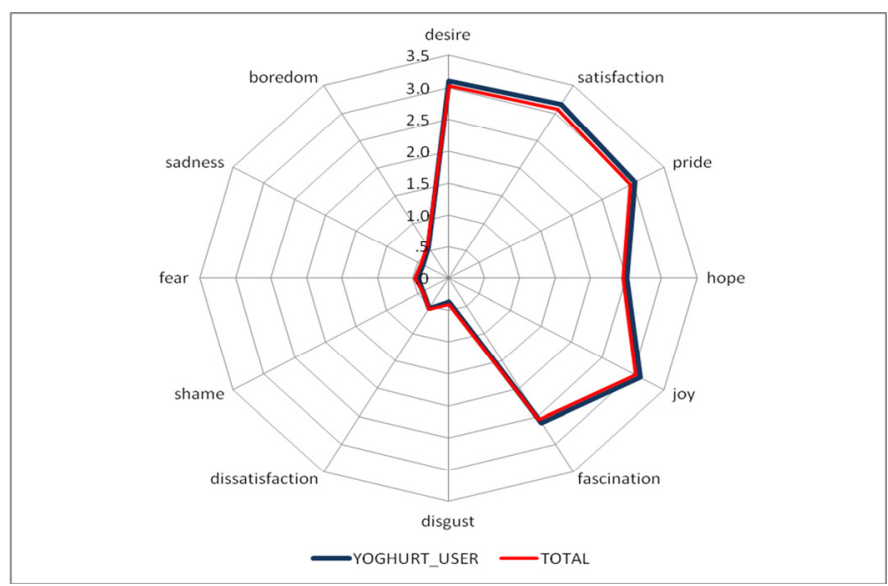

Figure 5. PrEmo yoghurt users versus total

The user and total participant profiles reflected in Figure 5 are, as with milk and cheese, similar in shape and distribution. However, the level is marginally higher indicating stronger positive emotions evoked as opposed to milk and cheese. Desire, Satisfaction, Joy and Pride remain the salient emotions experienced. 


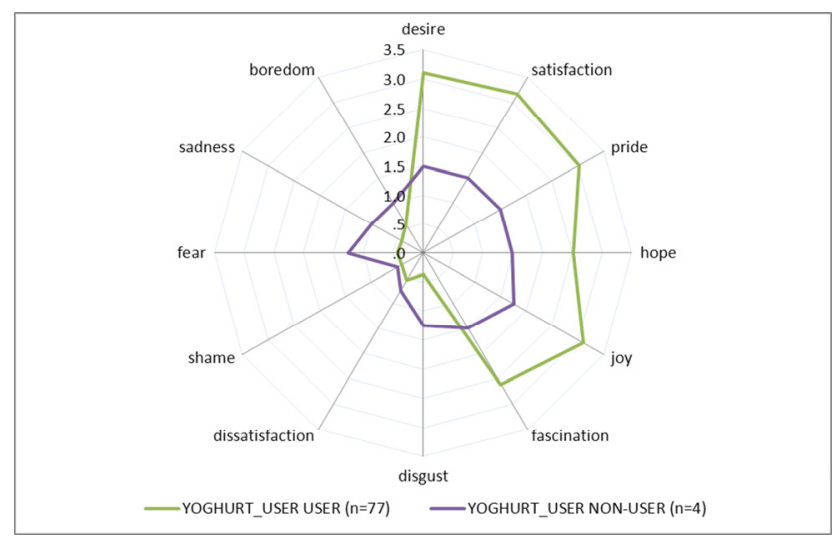

Figure 6. PrEmo yoghurt users versus non-users

Figure 6 indicates that the user and non-user profiles of yoghurt differ in level and distribution. It is evident that the positive profile displays a similar shape for both users and non-users, which indicates the more positive image that yoghurt enjoys among both users and non-users. It is also evident that non-users experience feelings of Fear, Disgust and Sadness when exposed to yoghurt.

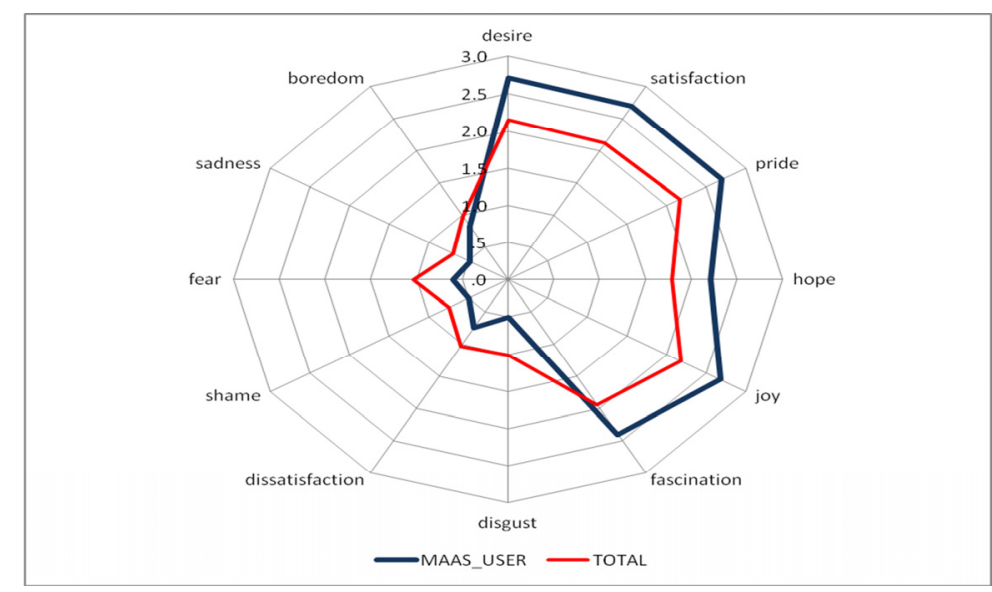

Figure 7. PrEmo maas users versus total

The user and total participant profiles portrayed in Figure 7 are, as with milk, yoghurt and cheese, similar in shape and distribution, specifically on Desire, Satisfaction, Pride, Hope, Joy, Fascination, Dissatisfaction, Shame and Fear. The level is substantially lower compared to that of the other products, indicating less intense positive emotions evoked by maas. 


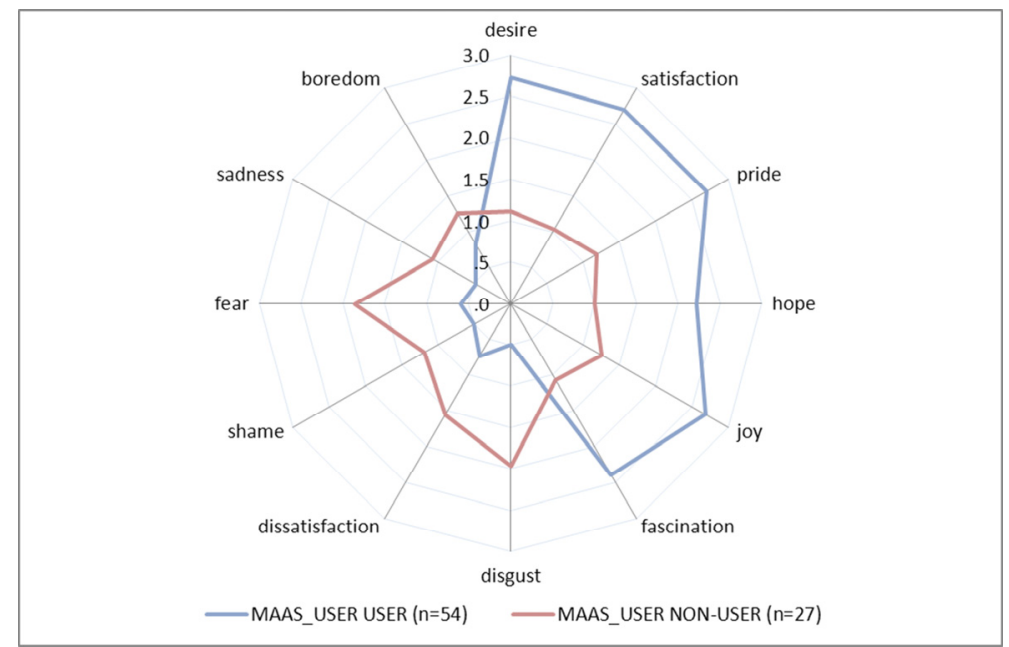

Figure 8. PrEmo Maas users versus non-users

According to Figure 8 the user and non-user profiles of maas differ significantly in shape, level and distribution. However, the positive profile displays an equivalent shape for both users and non-users with regards to Pride, Hope and Joy. Non-users appear to experience strong negative feelings of Fear and Disgust when exposed to maas.

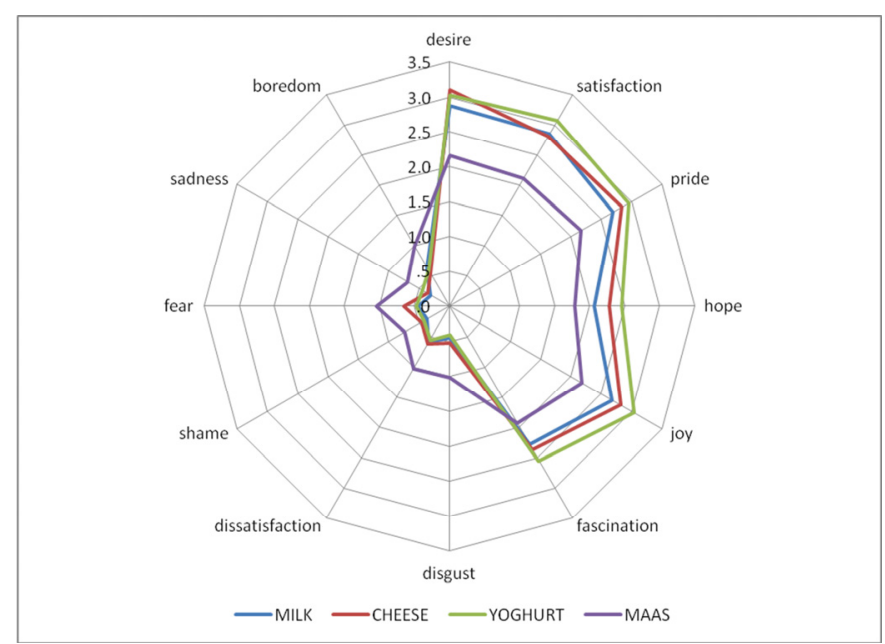

Figure 9. PrEmo all dairy products

Figure 9 conceptually illustrates the positive emotive reactions elicited by being exposed to all four dairy products. Exposure to yoghurt evoked stronger positive emotions on Satisfaction, Pride, Hope, Joy and Fascination, followed by cheese and milk. Despite maas depicting lower positive emotions, the similar shape and distribution to the other products could be indicative of a smaller maas user base, although they experience similar positive emotions to users of the other three products.

\section{Conclusion and Managerial Implications}

Consumer engagement is a dynamic and multidimensional concept. According to Paolocci (2014), organisations wishing to implement it should understand it as the result of an interactive dialogue with their target markets in order to have increased consumer knowledge for value creation.

This article focuses on determining the actual consumer feeling-related reactions associated with milk, yoghurt, cheese and maas and more specifically, the emotions that each of the selected products elicits in consumers in Gauteng, South Africa. With regards to the emotive reactions to the four dairy products included for the purposes of this study, the products do differ with yoghurt, cheese and milk evoking stronger positive emotions than maas. Milk, cheese and yoghurt all evoke feelings of Desire, Satisfaction, Joy and Pride with varying emotive 
intensities. Maas, on the contrary, evoked feelings of Hope and Fascination in addition to Desire, Satisfaction, Pride and Joy. Overall, yoghurt evoked the most intense emotions on Satisfaction, Pride, Hope, Joy and Fascination, followed by cheese and milk. However, the intensities of these emotions are substantially lower for maas.

\section{Limitations and Directions for Future Research}

The study being primarily qualitative in nature is not dependent on large samples. It has been found that smaller sample sizes (less than 120) are sufficient to provide understanding and strategic insight. It should also be noted that this study was only exploratory in nature, and prevents therefore the possibility of generalisation of the findings. However, it exhibits a strong interest in finding ways to engage with consumers.

The findings that are presented highlight the need to take into consideration the context-specific emotional dimensions of decision-making in relation to consumption of the dairy products under investigation. The study suggests that an exploration of consumer behaviour requires an understanding of 'individual consumption experiences' as a point of reference. These experiences will act as certain remembrance and judgemental values, and will greatly assist in devising basic strategies for increasing the amount of consumption, enhance the frequency of consumption and enhance the amount consumed per consumption.

\section{Acknowledgments}

Professor Pierre Joubert and Professor Annemarie Davis are acknowledged for their contribution to this research, and for their constructive comments on the previous version of this article.

\section{References}

Abubakar, M. M., \& Mokhtar, S. S. M. (2015). Impact of relational dynamics on customer loyalty in higher education sector: The moderating role of long term orientation. International Journal of Management Sciences, 5(3), 196-205.

Alba, J. W., \& Williams, E. F. (2012). Pleasure principles: A review of research on hedonic consumption. Journal of Consumer Psychology, 23(1), 2-18. http://dx.doi.org/10.1016/j.jcps.2012.07.003

Andrade, E. B., \& Cohen, J. B. (2007). On the consumption of negative feelings. Retrieved from http://www.haas.berkeley.edu/faculty/papers/AndradeCohen2007a.pdf

Argan, M. T., Argan, M., \& Akyildiz, M. (2014). Dimensions of consumption emotions: Turkish consumers' experiences. Journal of Marketing and Management, 5(1), 136-145.

Ariely, D., \& Norton, M. I. (2009). Conceptual consumption. Annual Review of Psychology, 60, 475-499. http://dx.doi.org/10.1146/annurev.psych.60.110707.163536

Bandama, M. (2011). Concentrated market power and information asymmetry within the South African dairy supply chain. Masters-thesis, University of Stellenbosch, Stellenbosch.

Bonnefoy-Claudet, L., \& Ghantous, N. (2013). Emotions' impact on tourists' satisfaction with ski resorts. The mediating role of perceived value. Journal of Travel \& Tourism Marketing, 6(30), 624-637. http://dx.doi.org/10.1080/10548408.2013.810999

Bordegoni, M. (2013). Invited talk user-product experience and emotions. Retrieved from http://ceur-ws.org/Vol-1065/paper1.pdf

Brink, A., \& Berndt, A. (2008). Customer relationship management and customer service. Landsdowne: Juta Academic.

Caru, A., \& Cova, B. (2003). A Critical Approach to Experiential Consumption: fighting against the disappearance of the contemplative time. Paper presented at 3rd International Critical Management Studies Conference, Lancaster University, July, 7-9.

Davis, S. (2002). Great brand building is just a touch away. Brandweek, 43(24), 16-20.

Department of Agriculture, Forestry and Fisheries. (2011). A profile of the South African dairy market value chain. Retrieved from http://www.daff.org.za

Desmet, P. M. A. (2002). Designing emotions. Doctoral thesis, Technische Universiteit Delft.

Drozdova, N. (2014). Measuring emotions in marketing and consumer behavior. Masters thesis, Norwegian School of Economics, Bergen. Retrieved from http://brage.bibsys.no/xmlui/bitstream/handle/11250/223267/masterthesis119.pdf?sequence=1 
Engle, J. F., Blackwell, R. D., \& Miniard, P. W. (1993). Consumer behavior (7th ed.). Chicago: the Dryden Press.

Erasmus, A. C., Boschoff, E., \& Rousseau, G. G. (2001). Consumer decision-making models within the discipline of consumer science: a critical approach. Journal of Family Ecology and Consumer Sciences, 29, 82-90.

Fokkinga, S., Hekkert, P., Desmet, P., \& Özcan, E. (2014). From product to effect towards a human-centered model of product impact. Retrieved from http://www.drs2014.org/media/655163/0386-file1.pdf

Goodwin, N., Nelson, J. A., Ackerman, F., \& Weisskopf, T. (2008). Consumption and the consumer society. Retrieved from http://www.ase.tufts.edu/gdae/education_materials/modules/consumption_and_the_consumer_society.pdf

Gutnik, L. A., Hakimzada, A. F., Yoskowitz, N. A., \& Patel, V. L. (2006). The role of emotion in decision-making: A cognitive neuroeconomic approach towards understanding sexual risk behavior. Journal of Biomedical Informatics, 39, 720-736. http://dx.doi.org/10.1016/j.jbi.2006.03.002

Holbrook, M. B., \& Hirschman, E. C. (1982). The experiential aspects of consumption: consumer fantasies, feelings, and fun. Journal of Consumer Research, 9, 132-140. http://dx.doi.org/10.1086/208906

Holbrook, M. B., Chestnut, R. W., Oliva, A. T., \& Greenleaf, E. A. (1984). Play as a consumption experience: The roles of emotions, performance, and personality in the enjoyment of games. Journal of Consumer Research, 11(2), 728-739. http://dx.doi.org/10.1086/209009

Honea, H., \& Horsky, S. (2011). The power of plain: Intensifying product experience with neutral aesthetic context. Marketing Letters, 23(1), 223-235. http://dx.doi.org/10.1007/s11002-011-9149-y

Hou, M., Xiaoding, W., \& Hu, Z. (2013). Personnel service, consumption emotion, and patronage intention in department stores. International Business Research, 6(3), 6-21. http://dx.doi.org/10.5539/ibr.v6n3p6

IBM Corp. (2015). IBM SPSS Statistics for Windows, Version 23.0. Armonk, NY: IBM Corp.

Johnston, R., \& Kong, X. (2011). The customer experience: a road-map for improvement. Managing Service Quality, 21(1), 5-24. http://dx.doi.org/10.1108/09604521111100225

Joubert, J. P. R, \& Poalses, J. (2014). The influence of emotions and personal values on packaging preference decisions. The International Retail and Marketing Review, 10(2), 60-76.

Kapoor, H. (2008). Negative emotions as motivators of consumption. In A. Y. Lee \& D. Soman (Eds.), NA-Advances in Consumer Research (vol. 35, pp. 949-950). Duluth, MN: Association for Consumer Research.

Kazakevičiūtè, A., \& Banytè, J. (2012). The relationship between retail crowding and consumers' satisfaction. Economics and Management, 17(2), 652-658. http://dx.doi.org/10.5755/j01.ee.23.5.1975

Keynes, J. M. (1936). The general theory of employment, interest and money. New York: Harcourt Brace.

Kim, Y., Sullivan, P., \& Forney, J. C. (2007). Experiential retailing: concepts and strategies that sell. New York: Fairchild Publications.

Krishna, A. (2010). Sensory marketing: Research on the sensuality of products. New York: Routledge.

LaSalle, D., \& Britton, T. A. (2003). Priceless: Turning ordinary products into extraordinary experiences. Boston, MA: Harvard Business School Press.

Lerner, J. S., Li, Y., Valdesolo, P., \& Kassam, K. (2014). Emotion and decision making. Annual Review of Psychology, 66(33), 1-25.

Li, M., Dong, Z. Y., \& Chen, X. (2011). Factors influencing consumption experience of mobile commerce: A

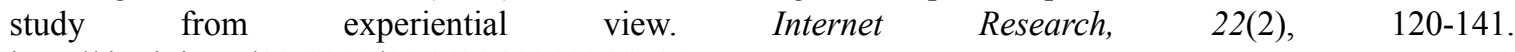
http://dx.doi.org/10.1108/10662241211214539

Lucier, G., \& Lin, B. (2001). Factors affecting watermelon consumption in the United States, Retrieved from http://www.agmrc.org/media/cms/WatermelonFactors_EFA697100FE6D.pdf

Mitchell, V. W., \& Walsh, G. (2004). Gender differences in German consumer decision making styles. Journal of Consumer Behavior, 3(4), 331-346. http://dx.doi.org/10.1002/cb.146

NAMC. (2001). Report on the Investigation into the Effects of the Deregulation of the Dairy Industry. National Agricultural Marketing Council (NAMC) Report No 07. March 2001.

O'Brien, H. L. (2010). The influence of hedonic and utilitarian motivations on user engagement: the case of online shopping experiences. Interacting with Computer, 22(5), 344-452. 
http://dx.doi.org/10.1016/j.intcom.2010.04.001

Paolocci, E. (2014). Digital strategies of consumer involvement and innovation dynamics: A Cross-sector explorative study. International Journal of Marketing Studies, 6(5), 21-39. http://dx.doi.org/10.5539/ijms.v6n5p21

Percy, L., Hansen, F., \& Randrup, R. (2004). How to measure brand emotion. Admap, 39(10, 455), 32-34.

Peter, J. P., \& Olson, J. C. (1987). Consumer behavior: Marketing strategy perspectives. Chicago: Irwin.

Pine II, B. J., \& Gilmore J. H. (1998). Welcome to the experience economy. Harvard Business Review, 76(4), 97-105.

Richins, M. L. (1997). Measuring emotions in the consumption experience. Journal of Consumer Research, 24(2), 127-146. http://dx.doi.org/10.1086/209499

Schiffman, L., \& Kanuk, L. L. (1997). Consumer behaviour (6th ed.). New Jersey: Prentice-Hall.

Schoefer, K. (2008). The role of cognition and affect in the formation of customer satisfaction judgements concerning service recovery encounters. Journal of Consumer Behaviour, 7(3), 210-221. http://dx.doi.org/10.1002/cb.246

Schroeder, J. E., \& Zwick, D. (2004). Mirrors of masculinity: representation and identity in advertising images. Consumption, Markets, and Culture, 7(1), 21-51. http://dx.doi.org/10.1080/1025386042000212383

Shien, L. W., \& Yazdanifard, R. (2014). Relationship marketing vs. internet marketing, which one contribute to gain higher level of consumer loyalty. Global Journal of Management and Business Research: E Marketing, 14(7), 40-48.

Sørensen, J. (2008). Measuring emotions in a consumer decision-making context-approaching or avoiding. Working Paper Series. Department of Business Studies.

Wanglee, S. (2013). The varying influences of positive emotions on consumption motivation. Contemporary Management Research, 9(2), 211-228. http://dx.doi.org/10.7903/cmr.10987

Yao, V. Y. (2013). Emotive reactions to the consumer education project of the South African dairy industry. University of South Africa, Pretoria.

\section{Note}

Note 1. Maas is the African name for sour milk sold in South Africa.

\section{Appendix}

\section{PrEmo animated character 5-point rating scale}
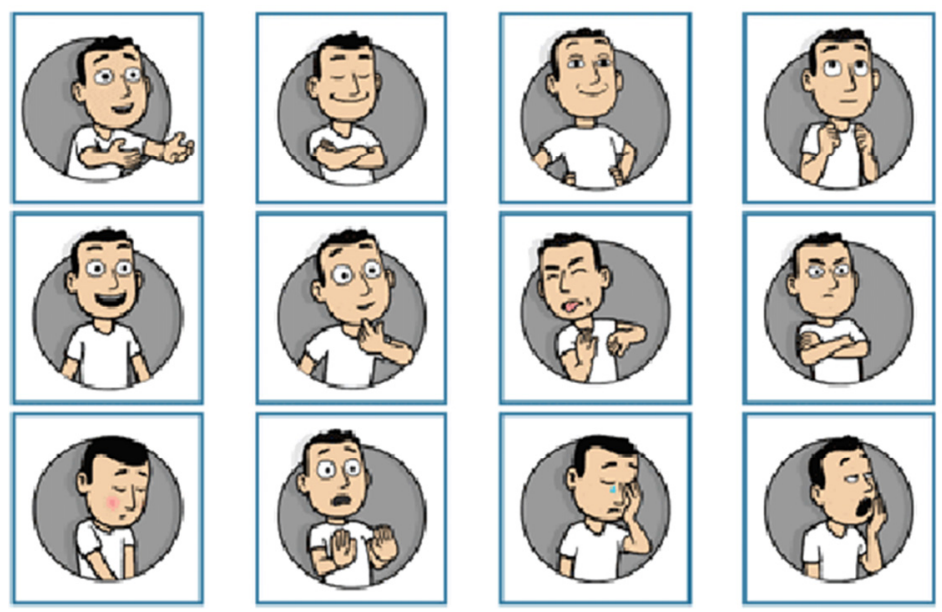

Source: Susa group, 2012. 


\section{Copyrights}

Copyright for this article is retained by the author(s), with first publication rights granted to the journal.

This is an open-access article distributed under the terms and conditions of the Creative Commons Attribution license (http://creativecommons.org/licenses/by/3.0/). 